\title{
Evaluation of the Endovascular Salvage Outcome for Dysfunctional Arteriovenous Fistula for Hemodialysis According To the Site of the Lesion: 3 Years Experience
}

\author{
*Usama Lotfi and Hisham Mostafa \\ Department of vascular surgery, Cairo University, Egypt
}

Submission: December 26, 2016; Published: January 09, 2017

*Corresponding author: Usama Lotfi, Professor of Vascular \& Endovascular Surgery, Department of vascular surgery, Faculty of medicine, Cairo University, Egypt, Tel: 201017384349; Email: usamalotfi@yahoo.com

\section{Abstract}

Background: Percutaneous transluminal angioplasty (PTA) has become an established treatment of dysfunctional arteriovenous fistula (AVFs). The outcome of such intervention is significantly influenced by the site of the underlying lesion.

Aim of the study: To focus on the impact of the site of the lesion(s) tackled on the immediate and delayed outcomes of endovascular salvage of dysfunctional AVFs in terms of technical success and 6 month patency rate; aiming at significant improvement in the management plan.

Patients and methods: This prospective study was carried out since January 2012 through August 2015. The study included 253 hemodialysis patients; 147 (58.1\%) males and 106 (41.8\%) females with a mean age of $58 \pm 15$ years. All patients had dysfunctional native AVFs that were subjected to endovascular salvage. The outcomes were evaluated in view of the site of underlying lesions.

Results: The dysfunction of the studied AVFs was caused by an underlying single lesion in 225 (88.9\%) cases; while multiple lesions were found in $28(11.1 \%)$ cases. The commonest site of lesions was encountered in the venous juxta-anastomotic segment $76(30 \%)$ and venous needling segment $61(24.1 \%)$. Technical success was achieved in $231(91.3 \%)$ patients. Recanalization was best achieved through transradial access in 191 (75.4\%) AVFs. Balloon angioplasty successfully recanalized 216 AVFs, while stenting was needed in 15 patients. No major complications have been recorded. Follow up period ranged from 6-20 (mean $8 \pm 5.3$ ) months. The overall primary patency rates were $88.3 \%$ and $71.4 \%$ at 1 and 6 months respectively. Technical success and patency rates were recorded according to site stratification.

Conclusion: The site of the lesion has an impact on the outcome of endovascular salvage of dysfunctional AVF with variable immediate success and later patency rates. Arterial and central venous lesions have the least success and patency rates. However, unfavorable rates are not an invitation to regret from paying effort for salvage. Simply, because intervention can be repeated, and more importantly, the use of suitable tools and techniques can optimize the results according to each lesion site.

Keywords: Endovascular; Arteriovenous fistula; Dysfunction; Salvage; Site of lesion.

Abbreviations: PTA: Percutaneous Transluminal Angioplasty; AVFs: Arterio-Venous Fistula; HD: Hemo-Dialysis; ESRD: End-Stage Renal Disease; PSVR: Peak Systolic Velocity Ratio; NIH: Neointimal Hyperplasia

\section{Introduction}

The provision of hemodialysis (HD) for patients with endstage renal disease (ESRD) requires a well functioning vascular access [1]. The best access for HD is the one that suit every patient individually. Durability is the concerned criterion in whatever the type of the access is. Under such heading comes the word "patency" whether primary, assisted primary, or secondary. Among the available accesses, the native AVF stands as the option with better overall patency and lower complication rates. However, when dysfunction is encountered in them, this represents a major cause of morbidity, mortality and significant HD care-related costs [2].

Until the near past, a dysfunctional AVF was synonymous with a temptation to decide a new access with resultant numerous procedures to maintain a safe HD and eventual 
exhaustion of all access sites. The introduction and evolution of endovascular techniques hold promise to salvage these AVFs that is to transform non-maturing, stenosed, or thrombosed fistulas to functioning fistulas again $[3,4]$. The site of lesion responsible for AVF dysfunction is a crucial factor from different aspects regarding the pathology, clinical presentation, and the way \& outcome of treatment. Such lesions might be confronted in the arterial side, anastomotic, or in the venous side with variable site stratifications. The aim of this study is to focus on the impact of the site of the lesion(s) tackled on the immediate and delayed outcomes of endovascular salvage of dysfunctional AVFs in terms of technical success and 6 month patency rate; aiming at significant improvement in the management plan.

\section{Patients and Methods}

This prospective study was conducted mainly in Kasr El Aini - Cairo University hospitals since January 2012 through August 2015. It included 253 HD patients with dysfunctional native AVFs. They were 147 (58.1\%) males and 106 (41.8\%) females. Their mean age was $58 \pm 15$ years. Dysfunctional autogenous AVFs belonged to one of three common upper limb types whether radiocephalic, brachiocephalic, or brachiobasilic fistulas. Patients with persistent hypotension, associated infection, overlying skin integrity disruption, or known contrast allergy were excluded from the study.

All patients were scheduled for endovascular salvage of their dysfunctional AVF after proper clinical and radiological assessment in one hand and after obtaining the ethical approval from the faculty research committee and informed written consent from the patients in the other hand. Clinical assessment included revision of the main presentation then assessment of the targeted upper limb in general, and the fistula in particular. The upper limb was evaluated for blood pressure, pulsations, scars, upper limb oedema, and the presence \& distribution of dilated veins. The current fistula was evaluated regarding its type, duration since creation, time lapse since dysfunction or cessation, aneurysmal dilatation, thrill propagation, overlying "water hammer" pulsations, and venous thrombus load as detected by palpation.

Radiological assessment was done for all patients. The protocol was to visualize the arterial tree starting from the subclavian down to the radial and ulnar arteries then assessment of the anastomotic site and the outflow up to the subclavian and/or the innominate veins. Duplex assessment targeted three aspects: a) The lesion morphology including number, site, severity, and length of each lesion,

b) The current access hemodynamic including flow rate (vessel cross sectional area $\mathrm{x}$ mean velocity), peak systolic velocity (PSV), and Peak systolic velocity ratio (PSVR), and

c) The suitability of the radial artery as an endovascular access (caliber, origin from the brachial artery, and its relative contribution with ulnar artery in hand circulation).

The scope of clinical and radiological assessment was centered on the exact site of the lesion(s). Accordingly, lesions were stratified as: arterial (Proximal), arterial (Juxta-anastomotic), anastomotic, venous (Juxta-anastomotic), needling segment, junctional (Entry of the fistula vein into the deep system), and central venous lesions. Endovascular AVF salvage was offered for all patients using standard endovascular techniques via the trans-radial, trans-venous, or less commonly trans-brachial approaches. Femoral venous approach was occasionally needed in certain situations. Two or more endovascular accesses were mandatory in some cases. Standard balloons were used in most of patients unless encountering non-dilatable persistent lesions where high pressure balloons were used. A hybrid procedure was needed in some cases when an open thrombectomy was added to deal with heavy venous thrombus load or when an acute arterial occlusion unintentionally ensued while dealing with juxta-anastomotic lesions. Self expanding stents were used in recanalized central venous lesions.

The parameters of successful procedure were defined by
A. Anatomic success: restoration of luminal diameter with less than $30 \%$ residual diameter stenosis.
B. Clinical success: improvement of clinical parameters with at least 3 sessions of successful HD, and
C. Hemodynamic success: the restoration of hemodynamic parameters (PSVR<2) [5-9].
Unless contraindicated, Enoxaparin Sodium twice daily S.C and Hirudin cream QDS topically were used routinely in successful cases for 5 days. Uneventful patients were advised to use their salvaged fistula for dialysis in the next day after the procedure and followed up after 1 week, 1 month, 3 months, and 6 months regarding the efficiency of dialysis, primary patency rate, and incidence of complications. All the data were collected and presented as mean, standard deviation, and percentages.

\section{Results}

Table 1: Patients demographics, co-morbidities, and baseline clinical characteristics.

\begin{tabular}{|c|c|}
\hline Characteristics & Value \\
\hline Age (years), Mean \pm SD*, range $^{*}$ & $58 \pm 15(12-65)$ \\
\hline Gender (Male : Female) & $147(58.1 \%): 106(41.8 \%)$ \\
\hline
\end{tabular}


Journal of Cardiology \& Cardiovascular Therapy

\begin{tabular}{|c|c|c|}
\hline \multicolumn{2}{|c|}{ Hypertension } & $169(66.7 \%)$ \\
\hline \multicolumn{2}{|c|}{ Diabetes } & $119(47 \%)$ \\
\hline \multicolumn{2}{|c|}{ Coronary artery disease } & $66(26 \%)$ \\
\hline Clinical presentations & $\begin{array}{l}\text { Change in the physical characteristics of the } \\
\text { thrill. } \\
\text { Inability to puncture the vein. } \\
\text { Swollen extremity. } \\
\text { Elevated negative arterial pre-pump } \\
\text { pressures. } \\
\text { Elevated venous pressures. } \\
\text { Prolonged bleeding after needle withdrawal. } \\
\text { Inefficient dialysis. }\end{array}$ & $\begin{array}{c}13(5.1 \%) \\
105(41.5 \%) \\
25(9.8 \%) \\
11(4.3 \%) \\
12(4.7 \%) \\
70(27.6 \%) \\
17(6.7 \%)\end{array}$ \\
\hline
\end{tabular}

A total of 253 patients (147 males and 106 females) were included in the study. Their mean age was $58 \pm 15$ years (range, 12-65 years). Co-morbidities included hypertension (66.7\%), diabetes (47\%) and coronary artery disease (26\%). The most common clinical presentations for dysfunctional AVF were inability to puncture the vein $(41.5 \%)$ and prolonged bleeding after needle withdrawal (27.6\%). The target lesions were confirmed by duplex assessment and were considered significant if the stenosis exceeded $50 \%$ of normal vessel diameter [5] (Table 1).

\section{*SD $=$ standard deviation}

Table 2: shows the site of lesions among the different types of AVFs.

Table 2: shows the site of lesions among the different types of AVFs.

\begin{tabular}{|c|c|c|c|c|c|c|c|c|}
\hline & \multirow{4}{*}{ Lesion site } & \multirow{4}{*}{ AVFs $n(\%)$} & \multicolumn{2}{|c|}{ Radiocephalic } & \multicolumn{2}{|c|}{ Brachiocephalic } & \multicolumn{2}{|c|}{ Brachiobasilic } \\
\hline & & & Right & Left & Right & Left & Right & Left \\
\hline & & & \multicolumn{2}{|c|}{$151(59.6 \%)$} & \multicolumn{2}{|c|}{$78(30.8 \%)$} & \multicolumn{2}{|c|}{$24(9.4 \%)$} \\
\hline & & & $\begin{array}{c}51 \\
(20.1 \%)\end{array}$ & $\begin{array}{c}100 \\
(39.5 \%)\end{array}$ & $\begin{array}{c}30 \\
(11.8 \%)\end{array}$ & $\begin{array}{c}48 \\
(18.9 \%)\end{array}$ & $\begin{array}{c}9 \\
(3.5 \%)\end{array}$ & $\begin{array}{c}15 \\
5.9 \%)\end{array}$ \\
\hline \multirow{7}{*}{$\begin{array}{l}\text { Single } \\
\text { lesions }\end{array}$} & Arterial proximal & $7(2.7 \%)$ & 2 & 3 & -- & 1 & 1 & -- \\
\hline & $\begin{array}{l}\text { Arterial Juxta- } \\
\text { anastomotic }\end{array}$ & $10(3.9 \%)$ & 3 & 2 & 2 & 1 & -- & 2 \\
\hline & Anastomotic & $33(13 \%)$ & 12 & 15 & 2 & 2 & 1 & 1 \\
\hline & $\begin{array}{l}\text { Venous Juxta- } \\
\text { anastomotic }\end{array}$ & $76(30 \%)$ & 12 & 30 & 12 & 17 & 1 & 4 \\
\hline & Needling segment & $61(24.1 \%)$ & 7 & 27 & 6 & 15 & 3 & 3 \\
\hline & Junctional & $16(6.3 \%)$ & 6 & 6 & -- & 2 & -- & 2 \\
\hline & Venous central & $22(8.6 \%)$ & 5 & 9 & 2 & 3 & 2 & 1 \\
\hline \multicolumn{2}{|c|}{ Multiple $(\geq 2)$ lesions } & $28(11.1 \%)$ & 4 & 8 & 6 & 7 & 1 & 2 \\
\hline
\end{tabular}

The mean duration since AVF creation to first intervention was $7.9 \pm 7.5$ months (range 2.5 to 46 months). The type of dysfunctional AVF was either radiocephalic, brachiocephalic, or brachiobasilic in an incidence of $59.6 \%, 30.8 \%$, and $10.2 \%$ respectively. The dysfunction of the studied AVFs was caused by an underlying single lesion in 225 (88.9\%) cases while multiple $(\geq 2)$ lesions were found in $28(11 \%)$ cases; as $23(9.1 \%)$ cases had 2 lesions and 5 (1.9\%) had 3 lesions. The most commonly involved site was detected in the juxta-anastomotic segment, while the least common site was found in the proximal arterial segment (Table 2) (Figures 1-3). 


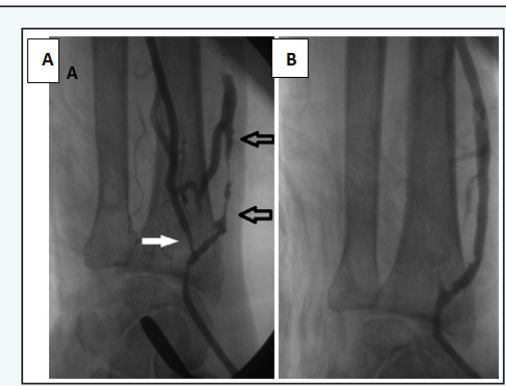

Figure 1: PTA of left failing radio cephalic AVF using a transradial access. A) Juxta-anastomotic lesions on both the venous side (black arrow) and arterial side (white arrow). B) Post balloon angioplasty of both the venous and arterial limbs of the fistula showing free flow of the contrast along the vein and obscuring the artery.

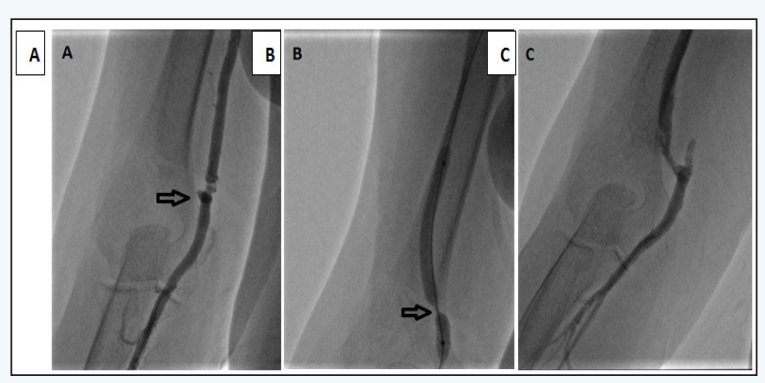

Figure 2: PTA of left brachiocephalic AVF using trans-radial access. A) Anastomotic lesion (black arrow). B) Balloon dilatation. C) Successful recanalization of the fistula and obscuring the artery.

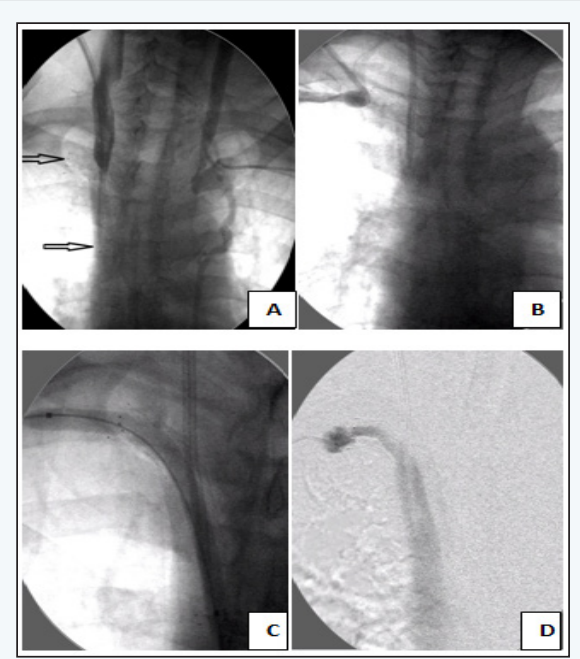

Figure 3: A) Left Trans-radial angiogram for venous hypertension patient with totally occluded left in nominate vein. Right sided non-cuffed catheter was used for temporary $\mathrm{HD}$ as the right side has an abandoned brachiocephalic AVF with a stented right in nominate vein \& SVC 2 year's earlier (black arrows). B) Right Trans-radial angiogram shows occluded stent. C) Successful wire crossing and balloon angioplasty of the stented veins. D) Final result showing free flow of the contrast through the stented segment down the superior vena cava (SVC).

Trans-radial access was solely the route of choice in 135 (53.3 \%) AVFs, and in combination with other access in 56 (22.1\%)
AVFs. Trans-venous access (through venous limb of the AVF) was resorted to in 61 patients $(24.1 \%)$ when a segment of the venous outflow tract was still patent distal to the anastomosis site especially when there was a limitation to puncture the radial artery. Double trans-venous access was needed in 27 patients (10.6\%) having total occlusion of their venous outflow tract; one was directed towards the anastomosis and the other was directed towards the central venous outflow with an overlapping segment in between, (Figure 4). Trans-femoral access was needed mainly in patients with central venous occlusions especially when an ante-grade wire crossing had failed, (Figure 5).
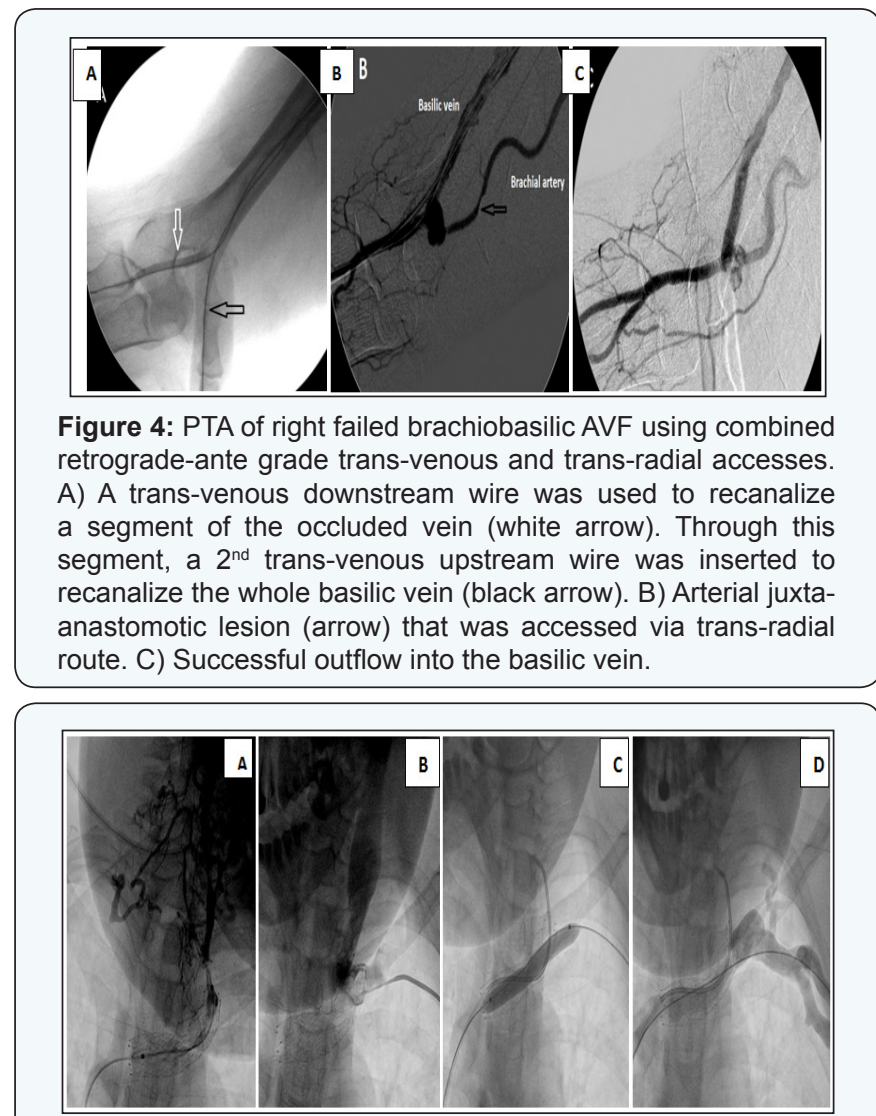

Figure 5: PTA of an occluded left in nominate venous stent in severe venous hypertension patient having left brachiocephalic AVF. A) Right Trans-femoral access: angiogram showed occluded stent with enhancement of the internal jugular vein (IJV) tributaries. B) Trans-venous access via the fistula shows near total occlusion of the in nominate venous stent with reversal of the jugular venous flow. C) Successful wire crossing through the stent struts and balloon dilatation. D) Final angiogram shows good flow of the contrast through the dilated in- stent restenosis down to the SVC and obscuring the IJV.

Anatomic success was achieved in 231/253 (91.3\%) patients; whether directly through recanalization of the whole fistulous tract $(n=219)$ or through recanalizing part of it then diverting the blood flow to a patent deeper vein $(n=12)$ (Figure 6). Balloon angioplasty using standard balloons could successfully recanalize 216 patients. High pressure balloons were mandatory in 14 cases (Figure 7). Fifteen self expandable stents were used in those with central venous lesions (Figure 8). 


\section{Journal of Cardiology \& Cardiovascular Therapy}

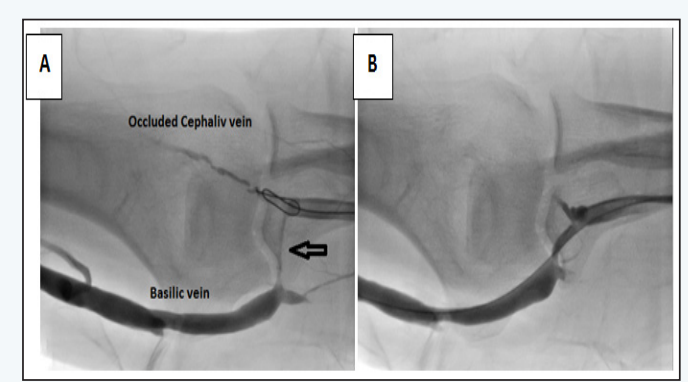

Figure 6: PTA of left radiocephalic AVF. A) Occluded cephalic vein above the elbow with a patent stenotic median cubital vein (arrow). B) Successful outflow into the basilic vein.

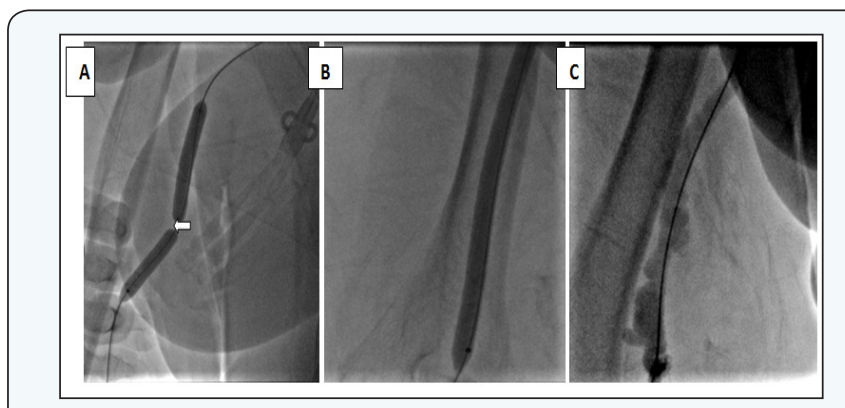

Figure 7: PTA of right brachiobasilic AVF using trans-radial access. A) Standard balloon couldn't dilate a resilient stenosis in the needling segment with characteristic waist (arrow). B) High pressure balloon could overcome the lesion. C) Successful recanalization of the fistula and obscuring the artery.

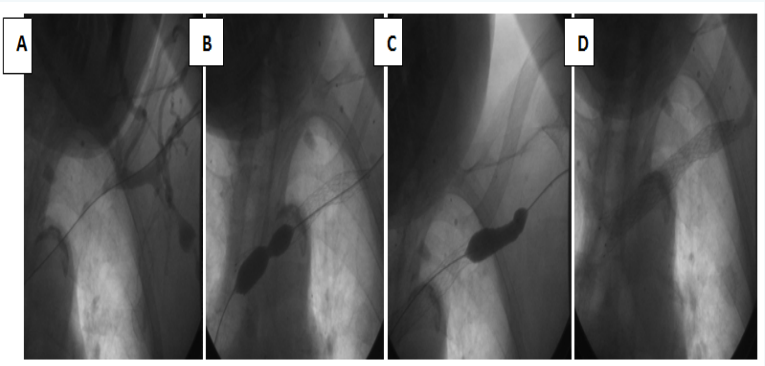

Figure 8: PTA of central venous occlusion in a venous hypertension patient having left radiocephalic AVF through its venous limb. A) Successful wire crossing the totally occluded left subclavian and in nominate veins. B\&C) Stenting the lesion with post deployment balloon dilatation. D) Final result showing free flow of the contrast through the stented segment down the SVC.

Venous thrombectomy of heavy thrombus load was needed in 11 patients; additionally 2 of them required arterial thrombembolectomy due to the development of an acute ischemic episode while managing a venous juxta-anastomotic lesion and the procedure was successfully completed. The technique has failed in $22(8.6 \%)$ patients. The most common cause was failure to cross the lesion in 13 AVFs; (Eight patients with central, and 5 with peripheral venous lesions). Other reasons included persistent false passage $(n=3)$, uncontrollable rupture $(n=2)$, resilient non-dilatable lesion in spite of high pressure balloon dilatation $(n=2)$, immediate vascular steal $(\mathrm{n}=1)$, and contrast allergy $(\mathrm{n}=1)$.
Other complications included minor hematoma that was encountered in 7 patients who were managed conservatively. Another 2 expanding hematomas necessitated ligation of the fistula. A circumferentially ruptured balloon material required extraction while performing a successful PTA for radio cephalic AVF (Table 3).

Table 3: Procedure details and outcome.

\begin{tabular}{|c|c|c|c|}
\hline \multicolumn{3}{|c|}{ Parameter } & Number \\
\hline \multirow{5}{*}{ Access site } & \multirow{5}{*}{$\begin{array}{l}\text { - Trans-radial. } \\
\text { - Trans-venous (venous } \\
\text { limb of the AVF). } \\
\text { - Trans-brachial. } \\
\text { - Trans-femoral (Common } \\
\text { femoral vein). }\end{array}$} & Single & Combined \\
\hline & & 135 & 56 \\
\hline & & 42 & 19 \\
\hline & & 5 & 2 \\
\hline & & -- & 14 \\
\hline \multirow{2}{*}{$\begin{array}{l}\text { Successful } \\
\text { recanalization } \\
(n=231)\end{array}$} & $\begin{array}{c}\text { - Direct increase of blood } \\
\text { flow through the AVF } \\
\text { outflow vein }\end{array}$ & \multicolumn{2}{|c|}{219} \\
\hline & $\begin{array}{l}\text { - Indirect increase of } \\
\text { blood flow through a } \\
\text { deep patent vein }\end{array}$ & \multicolumn{2}{|c|}{12} \\
\hline \multirow{4}{*}{ Procedure } & $\begin{array}{c}\text { - PTA (with } \\
\text { thrombectomy in } 11 \\
\text { cases) }\end{array}$ & \multicolumn{2}{|c|}{$216(85.3 \%)$} \\
\hline & - Standard balloon & \multicolumn{2}{|c|}{$202 / 216$} \\
\hline & - High pressure balloon & \multicolumn{2}{|c|}{$14 / 216$} \\
\hline & PTA + Stent & \multicolumn{2}{|c|}{$15(5.9 \%)$} \\
\hline \multirow{6}{*}{$\begin{array}{l}\text { Failed cases } \\
\qquad(n=22)\end{array}$} & $\begin{array}{c}\text { - Failure to cross the } \\
\text { lesion }\end{array}$ & \multicolumn{2}{|c|}{$13(5.1 \%)$} \\
\hline & - Persistent false passage & \multicolumn{2}{|c|}{$3(1.18 \%)$} \\
\hline & - Uncontrollable rupture & \multicolumn{2}{|c|}{$2(0.79 \%)$} \\
\hline & $\begin{array}{l}\text { - Resilient non-dilatable } \\
\text { lesion }\end{array}$ & \multicolumn{2}{|c|}{$2(0.79 \%)$} \\
\hline & - Immediate vascular & \multicolumn{2}{|c|}{$1(0.39 \%)$} \\
\hline & $\begin{array}{c}\text { steal } \\
\text { - Contrast allergy }\end{array}$ & \multicolumn{2}{|c|}{$1(0.39 \%)$} \\
\hline \multirow{7}{*}{ Complications } & $\begin{array}{l}\text { - Acute ischemia } \rightarrow \\
\text { Thrombembolectomy } \\
\text { (successful PTA) }\end{array}$ & \\
\hline & $\begin{array}{l}\text { - Minor hematoma } \rightarrow \\
\text { conservative treatment }\end{array}$ & \multicolumn{2}{|c|}{2} \\
\hline & (successful PTA) & \multicolumn{2}{|c|}{7} \\
\hline & - Foreign body embolism & \multicolumn{2}{|r|}{1} \\
\hline & $\begin{array}{c}\rightarrow \text { extraction (successful } \\
\text { PTA) }\end{array}$ & \multicolumn{2}{|r|}{2} \\
\hline & $\begin{array}{c}\text { - Expanding hematoma } \rightarrow \\
\text { AVF ligation }\end{array}$ & \multirow{2}{*}{\multicolumn{2}{|c|}{1}} \\
\hline & $\begin{array}{l}\text { - Contrast allergy } \rightarrow \\
\text { Aborted procedure }\end{array}$ & & \\
\hline
\end{tabular}

All 231 patients whose AVFs were salvaged successfully were followed up for a minimum of 6 months with a mean follow-up duration of $8 \pm 5.3$ (range 6-20) months. The fistula had to be 
abandoned due to occlusion or dysfunction during dialysis in $30(12.9 \%)$ of the 231 patients. Fifty eight (25.1\%) patients required a total of 77 repeat endovascular treatments as 2ry PTAs that were performed for single stenosis in 25 AVFs and for multiple stenoses in 33 AVFs [6-9]. The overall 1ry patency rate was $88.3 \%$ and $71.4 \%$ at 1 and 6 months, respectively. In single lesions' AVFs, 1ry patency rates were $90.3 \%$ and $75.4 \%$ at 1 and 6 months respectively; while in multiple lesions' AVFs, the 1ry patency rates where $69.5 \%$ and $34.7 \%$ respectively (Table 4 ).

Table 4: 1ry patency rates in different lesions.

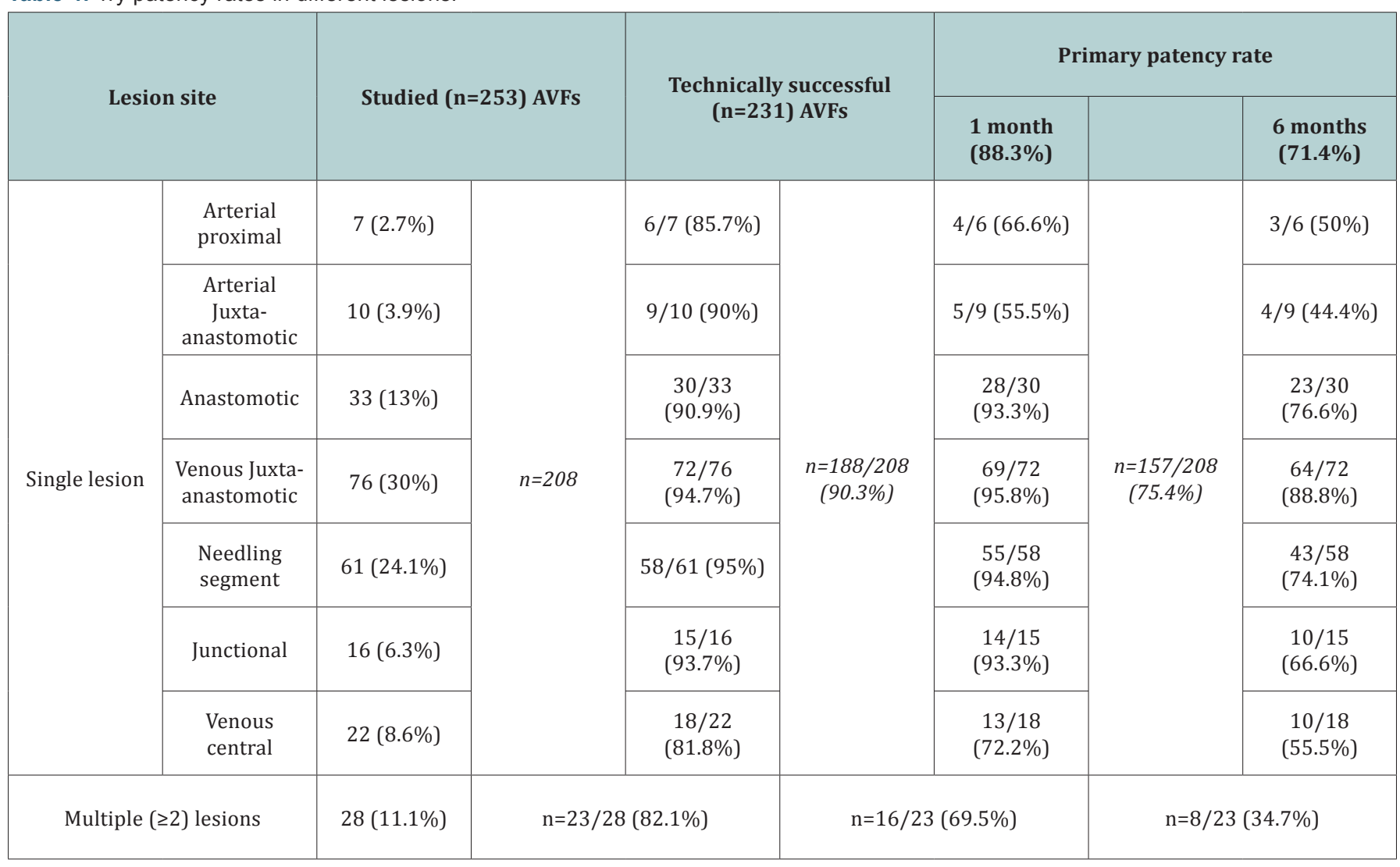

\section{Discussion}

The superiority of autogenous AVFs in general when compared with artificial grafts and dialysis catheters is well documented in the literature $[10,11]$. Although better patency is the keyword; yet, an incidence of some failures among them are there. This can be attributed to the development of stenoses leading to their dysfunction that eventually ends by either reintervention or creation of a new fistula [12]. Reintervention using the PTA strategy offers a chance for salvage of the current dysfunctional AVFs with sparing of the other possible venous sites especially if their number is limited [13]. The collaboration of several factors contributes in the high likelihood of occurrence of stenoses in an autogenous AVF.

It is believed that the mere establishment of anastomosis between a high-pressure arterial system and a low-pressure venous one is sufficient to generate tangential wall shear stress, compliance mismatch, and flow turbulence throughout the circuit [14]. All these mechanical factors impart a biological response "mechanotransduction" leading to continuous neointimal hyperplasia (NIH) formation [15-19]. A more popular explanation for the liability of juxta-anastomotic segment to stenosis is that dissection, mobilization, and swinging during AVF creation might deprive it from its blood supply [20-23]. However, similar circumstances for the dissected re-tunneled basilic vein don't end into the same consequences. In the current study, venous juxta-anastomotic segment being the seat of considerable degree of mechano transduction and hence $\mathrm{NIH}$ load, showed the highest incidence of stenosis (30\%).

From the analytic point of view, the site of the lesion comprises a crucial cornerstone for influencing the outcome of endovascular salvage of dysfunctional AVFs. Such influence can be explained by the difference in the etiopathology including exposure to the mechanical factors, the strategic location of the lesion in the circuit with the impact of the anatomical surrounding structures, and the vulnerability of specific segments for repetitive trauma.

To the best of our knowledge, there is limited evidence in the literature concerning the patency rates according to different lesion sites following endovascular salvage for dysfunctional AVFs. The overall 1ry patency rates were $61 \%$ and $42 \%$ at 6 months and 12 months respectively in a study that evaluated the outcomes and durability of PTA for 159 stenoses of AVFs, 
with or without stenting [24]. Another study had reported early recurrence rate of $23.2 \%$ within 6 months in spite of high technical (96.3\%) and clinical success (97.2\%) [25]. While the clinical success, technical success, and 1ry patency rates were $95.7 \%, 86.5 \%$, and $71.9 \%$ respectively in another study that evaluated the anatomical causes of maturation failure and assessing clinical outcomes after the causative lesions of immature AVF corrected by endovascular treatment [26].

In the current study, the 6 months 1ry patency rate after endovascular salvage for dysfunctional AVFs due to arterial lesions was $44.4-50 \%$ and those due to anastomotic lesions was $76.6 \%$. Whereas the 6 months 1ry patency rates following PTA for venous lesions were as follows: venous juxta-anastomotic $(88.8 \%)$, needling segment $(74.1 \%)$, junctional $(66.6 \%)$, and (55.5\%) after PTA and stenting for venous central lesions.

From the etiopathological point of view, NIH plays an integral role in restenosis after PTA wherever the site of the lesion. Additive pathology varies from atherosclerosis in the arterial side, technical problem at the anastomotic site, and fibrosis \& residual thrombosis at the venous side.

\section{Conclusion}

In the current study, arterial lesions had a relatively high success rate (85.7-90\%), but on the contrary, they had the lowest patency rate (44.4-50\%); especially when multiple. This success rate can be attributed to both the site of the lesion (being on the high pressure side of the circuit) and its nature (being mostly soft atherosclerotic plaque). On the other hand, the poor patency rate was attributed to both progressions of atherosclerosis and/ or dissection during PTA with resultant NIH and thrombosis thereafter. Hence, the relatively good immediate outcome should be taken cautiously. In addition, it is recommended to minimize the incidence of post PTA dissection by using just the optimum balloon length required with minimal pressure (nominal) and long inflation (at least 2 minutes) when dealing with arterial lesions.

Among the different venous sites, juxta-anastomotic lesions carry the best 6 month patency rate $(88.8 \%)$ when compared with other venous sites. This can be explained by the lack of repetitive trauma which is peculiar to the needling segment (6 month patency rate is $74.1 \%$ ), and the lack of compression by the surrounding fascia which is met in junctional segment (6 month patency rate is $66.6 \%$ ).

Targeting a better patency rate for both the anastomotic and juxta-anastomotic lesions, we do postulate that refinement of the initial surgical technique could be of help to minimize the stenosis from the start and restenosis after PTA. Whereas in the needling segment, the puncture technique modulation would definitely be of great help to optimize the patency after PTA as this will affect the degree of restenosis and incidence of intravenous synechia along the pathway of the needle punctures. The challenge will be in the junctional lesions due to the impact of the surrounding fascia that leads to recoil after successful PTA minimizing the patency rate. And hence, the assisted surgical role is evoked to relieve such compression.

Central venous lesions had the worst success rate together with poor 6 month patency rates. This augments the major prophylactic role of the "fistula first" principle avoiding unnecessary HD central venous catheters insertion with their subsequent central venous pathology. It was found in the current study that tackling total central occlusions is much more difficult than similar peripheral lesions. So, in symptomatic cases, early intervention at the stenosis phase is better than delaying it till total occlusion ensues. This is attributed to coexistence of multiple factors responsible for total occlusion in one hand (including severe fibrosis, and organized thrombosis), and the presence of sizeable extensive collaterals in the other hand (that direct the wire away from the main pathway). Accordingly, to optimize the success rate, we have to optimize the access and tools. And to improve the patency rate, we have to consider venous stents, drug eluting technology, and proper surveillance.

The site of the lesion has an impact on the outcome of endovascular salvage of dysfunctional AVF with variable immediate success and later patency rates. Arterial and central venous lesions have the least success and patency rates. However, unfavorable rates are not an invitation to regret paying effort for salvage. Simply, because intervention can be repeated, and more importantly, the use of suitable tools and techniques can optimize the results according to each lesion site.

\section{References}

1. Yevzlin A, Asif A (2009) Stent placement in hemodialysis access: historical lessons, the state of the art and future directions. Clin J Am Soc Nephrol 4(5): 996-1008.

2. Sawant A, PK Mills, H Dhingra (2013) Increased length of stay and costs associated with inpatient management of vascular access failures. Semin Dial 26(1): 106-110.

3. Yury Bak, John H Cooper, Kane L Chang (2014) Endovascular Therapies for Hemodialysis Access: Case Presentations of Salvage, Surgical Maturation, and Maintenance. VASCULAR DISEASE MANAGEMEN 11(7): E145-E155.

4. George M. Nassar, Binh Nguyen, Edward Rhee, Katafan Achkar (2006) Endovascular treatment of the "failing to mature" arteriovenous fistula. Clinical Journal of the American Society of Nephrology 1(2): 275-280.

5. Clinical practice guidelines for vascular access (2006) Am J Kidney Dis 48(1): S176-247.

6. Gray RJ, Sacks D, Martin LG, Trerotola SO (2003) Reporting standards for percutaneous interventions in dialysis access. J Vasc Interv Radiol 14: S433-442.

7. Sidawy AN, Gray R, Besarab A, Henry M, Ascher E, et al. (2002) Recommended standards for reports dealing with arteriovenous hemodialysis accesses. J Vasc Surg 35(3): 603-610.

8. Trerotola SO, Ponce P, Stavropoulos SW, Clark TW, Tuite CM, et al. (2003) Physical examination versus normalized pressure ratio for predicting outcomes of hemodialysis access interventions. J Vasc Interv Radiol 14(11): 1387-1394.

9. Amin MZ, Vesely TM, Pilgram T (2004) Correlation of intragraft 
blood flow with characteristics of stenoses found during diagnostic fistulography. J Vasc Interv Radiol 15(6): 589-593.

10. Nassar GM, Ayus JC (2001) Infectious complications of the hemodialysis access. Kidney Int 60(1): 1-13.

11. Roy-Chaudhury P, BS Kelly, Melhem M, Zhang J, Li J, et al. (2005) Vascular Access in Hemodialysis: Issues, Management, and Emerging Concepts. Cardiol Clin 23(3): 249-273.

12. Lok CE, Sontrop JM, Tomlinson G, Rajan D, Cattral M, et al. (2013) Cumulative Patency of Contemporary Fistulas versus Grafts (20002010). Clin J Am Soc Nephrol. 8(5): 810-818.

13. S Heye, G Maleux, J Vaninbroukx, K Claes, D Kuypers, et al. (2012) Factors influencing technical success and outcome of percutaneous balloon angioplasty in de novo native hemodialysis arteriovenous fistulas. Eur J Radiol 81(9): 2298-2303.

14. Lee JM, Park J, Kang J, Jeon KH, Jung JH, et al. (2015) Comparison among drug-eluting balloon, drug-eluting stent, and plain balloon angioplasty for the treatment of in-stent restenosis: a network meta-analysis of 11 randomized, controlled trials. JACC Cardiovasc Interv 8(3): 382-394.

15. Rajan DK, Platzker T, Lok CE, Beecroft JR, Tan KT, et al. (2007) Ultrahighpressure versus high-pressure angioplasty for treatment of venous anastomotic stenosis in hemodialysis grafts: is there a difference in patency? J Vasc Interv Radiol 18(6): 709-714.

16. Aftab SA, Tay KH, Irani FG, Gong Lo RH, Gogna A, et al. (2014) Randomized clinical trial of cutting balloon angioplasty versus highpressure balloon angioplasty in hemodialysis arteriovenous fistula stenosis resistant to conventional balloon angioplasty. J Vasc intervent Radiol 25(2): 190-198.

17. Neuen BL, Gunnarsson R, Webster AC, Baer BA, Golledge J, et al. (2014) Predictors of patency after balloon angioplasty in hemodialysis fistulas: a systematic review. J Vasc Interv Radiol 25(6): 917-924.
18. Mantha M, Killen JP, Baer R, Moffat J (2011) Percutaneous maintenance and salvage of dysfunctional arteriovenous fistulae and grafts by nephrologists in Australia. Nephrology 16(1): 46-52.

19. Teo T, Tan BS, Yin W, R Lo, FG Irani, et al. (2013) Prospective randomized trial comparing drug-eluting balloon versus conventional percutaneous transluminal angioplasty (DEBAPTA) for the treatment of hemodialysis arteriovenous fistula or arteriovenous graft stenosisinterim report of first 30 patients. J Vasc Intervent Radiol 24(4): S40-S41.

20. Falk, V. Teodorescu, WY Lou, J Uribarri, JA Vassalotti (2003) Treatment of "swing point stenoses" in hemodialysis arteriovenous fistulae. Clin Nephrol 60(1): 35-41.

21. Vassalotti JA (2004) Arteriovenous fistula stenosis: New terminology. Semin Dial 17(3): 243.

22. Kian K, Vassalotti JA (2005) The new arteriovenous fistula: The need for earlier evaluation and intervention. Semin Dial 18(1): 3-7.

23.S Shenoy, RS Woodward (2005) Economic impact of the beneficial effect of changing vascular anastomotic technique in hemodialysis access. Vasc Endovasc Surg 39(5): 437-443.

24. Bountouris I, Kristmundsson T, Dias N, Zdanowski Z, Malina M (2014) Is Repeat PTA of a Failing Hemodialysis Fistula Durable? International journal of vascular medicine.

25. Ayse Aktas, Alper Bozkurt, Bulent Aktas, Ismail Kirbas (2015) Percutaneous transluminal balloon angioplasty in stenosis of native hemodialysis arteriovenous fistulas: technical success and analysis of factors affecting postprocedural fistula patency. Diagn Interv Radiol 21(2): 160-166.

26. Han M, Kim JD, Bae JI, Lee JH, Oh CK, et al. (2013) Endovascular treatment for immature autogenous arteriovenous fistula. Clinical radiology 68(6): e309-e315.

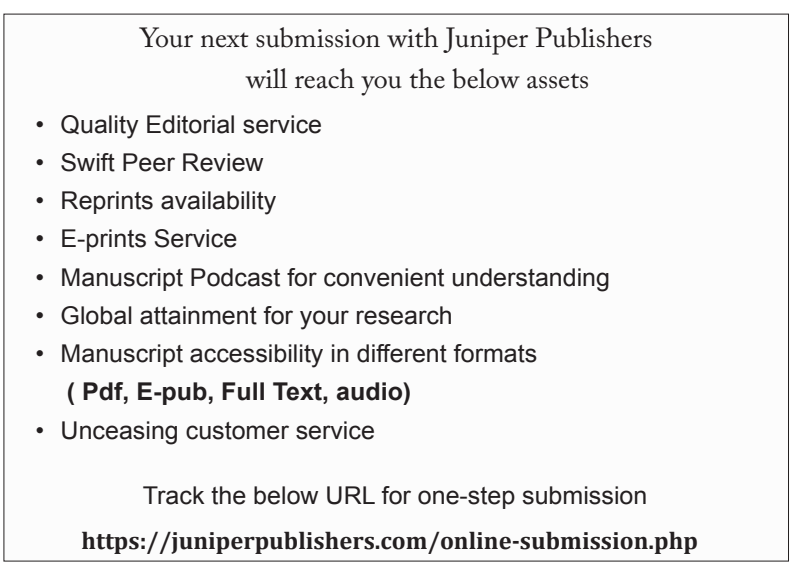

